\title{
Selenium nanoparticles produce a beneficial effect in psoriasis by reducing epidermal hyperproliferation and inflammation
}

\author{
Vinod Gangadevi ${ }^{\dagger}$, Sowjanya Thatikonda ${ }^{\dagger}$, Venkatesh Pooladanda, Geetanjali Devabattula and \\ Chandraiah Godugu*
}

\begin{abstract}
Background: Psoriasis is a chronic autoimmune skin disease characterized by hyperproliferation of keratinocytes. Wide treatment options used to treat psoriasis is associated with various adverse effects. To overcome this nanoformulation is prepared. Selenium is an essential trace element and plays major role in oxidation reduction system. Toxicity and stability limits the applications of selenium. Toxicity can be reduced and stabilized upon preparation into nanoparticles.

Results: Selenium nanoparticles (SeNPs) exhibit potent apoptosis through the generation of reactive oxygen species (ROS) with cell cycle arrest. SeNPs topical gel application produced significant attenuation of psoriatic severity with the abrogation of acanthosis and splenomegaly. SeNPs reduced the phosphorylation and expressions of MAPKs, STAT3, GSK-3ß, Akt along with PCNA, Ki67, and cyclin-D1.

Conclusion: SeNPs inhibit various inflammation and proliferation mediated pathways and could be an ideal candidate for psoriasis therapy.

Materials and methods: SeNPs were characterized and various techniques were used to determine apoptosis and other molecular mechanisms. In vivo studies were performed by inducing psoriasis with imiquimod (IMQ). SeNPs were administered via topical route.
\end{abstract}

Keywords: Psoriasis, Selenium nanoparticles, Reactive oxygen species, Inflammation, Proliferation, Imiquimod

\section{Introduction}

Psoriasis is an autoimmune chronic skin disease characterized by hyperproliferation of keratinocytes [1]. The amplification of dendritic cells and T-cells from the immune system releases various proinflammatory cytokines and chemokines with simultaneous activation of growth factors together involve in the pathogenesis of psoriasis [2]. The main histological and characteristic

\footnotetext{
*Correspondence: chandragodugu@gmail.com; chandra.niperhyd@gov.in †Vinod Gangadevi, Sowjanya Thatikonda contributed equally to this work Department of Regulatory Toxicology, National Institute of Pharmaceutical Education and Research (NIPER), Balanagar, Hyderabad, Telangana 500037, India
}

features of psoriasis are acanthosis, prominent dilated blood vessels in the dermis, and leukocyte infiltration [3]. Psoriatic keratinocytes possess an enhanced ability to endure apoptosis with a dramatic increase in cell cycle progression, which results in the elongation of rete ridges that protrudes into the dermis $[4,5]$. Epidemiological evidence suggests that psoriasis is affecting $2-3 \%$ population which is associated with pain and pruritus [6]. Moreover, psoriasis patients suffer from impaired quality of life with emotional distress and the burden of comorbidities such as hypertension [7], diabetes mellitus [8] and obesity [9] with the increase in the psoriasis severity. 
The activation of $\mathrm{T}$ helper (Th) cells including Th1, Th17, and Th22 cells trigger the inflammatory process of psoriasis and upregulate an array of proinflammatory cytokines [10], among, Th17 cells are the primary source of IL-22, which principally targets keratinocytes and orchestrates its effect through the activation of mitogen activated protein kinases (MAPKs) and signal transducer and activator of transcription 3 (STAT3) [11]. In keratinocytes, the growth factors which include epidermal growth factor (EGF), vascular endothelial growth factor (VEGF), and keratinocyte growth factor (KGF) majorly contribute to reinforcing the epidermal hyperplasia, angiogenesis and cell differentiation [12].

Topical corticosteroids remain the mainstay in psoriasis therapy with different potencies, but their long term usage leads to various adverse effects [13]. Although psoralen with UV-A (PUVA) is the effective psoriasis treatment, its use is diminishing because of its interconnection with malignancies. Methotrexate, tacrolimus, acitretin, and cyclosporine- $\mathrm{A}$ are the commonly used systemic or topical agents with high efficacy but prolonged usage is associated with systemic toxicity and other inherent side effects [14]. Biologicals such as adalimumab, infliximab, secukinumab, and ustekinumab are successful therapeutic options for psoriasis with good efficacy, for moderate to severe psoriasis [15]. Still, there is a substantial unmet clinical need to develop safer therapeutic approaches for long term usage.

Nanomedicine has evolved as a distinct method of treatment in therapeutics by overcoming the problems associated with conventional drug forms [16, 17]. Various other nanoparticle systems were used in treating psoriasis such as methotrexate containing gold nanoparticles [18] and silver nanopaticles [19]. The nanoparticles novel drug delivery systems offer enhanced therapeutic activity with fewer side effects in treating psoriasis [20]. Metal nanoparticles like Se, Au, Ag, Zn, $\mathrm{Ce}$, and Fe are widely used in various ailments, among which SeNPs are extensively used because of their captivating applications. [21]. Se exists as $\mathrm{Se}^{2+}, \mathrm{Se}^{4+}, \mathrm{Se}^{6+}$, $\mathrm{Se}^{2-}$ oxidation forms and its toxicity can be reduced upon the preparation into nanoparticle formulations [22]. SeNPs can be synthesized by various biological methods (i.e. from bacteria, fungi, plants) and other synthetic methods $[23,24]$. SeNPs has been explored as potent anticancer agents which increase the generation of ROS by the leakage of mitochondrial proteins and endoplasmic reticulum stress, leading to DNA damageinduced apoptosis [25]. SeNPs in combination has been found to overcome the systemic resistance of various chemotherapeutics such as 5- fluorouracil, irinotecan, and adriamycin with effective synergistic activity [26, 27]. On the other side, SeNPs are found to attenuate certain drug-induced toxicities like thyrotoxicity, nephrotoxicity, and genotoxicity [28]. Also, SeNPs are effective in treating the inflammation-driven disorders such as arthritis, liver fibrosis, as well as nephropathy, and the main mechanism behind the anti-inflammatory activity is through the reduction of inflammatory cytokines levels such as IFN- $\Upsilon$, IL- $1 \beta$, IL-12, IL-6, and IL-2 [29].

The current study aims to investigate the potential role of SeNPs in alleviating epidermal acanthosis and inflammation in psoriasis. SeNPs may shed light as a promising therapeutic treatment option on the proliferation and inflammation-driven psoriasis.

\section{Materials and methods}

\section{Chemicals and reagents}

Formaldehyde, Glycine, Potassium chloride, Tris- $\mathrm{HCl}$, Dimethyl sulphoxide (DMSO), Bicinchonic acid (BCA), Sodium dodecyl sulphate (SDS), Propidium iodide (PI), reduced glutathione (rGSH), 2', 7'-dichlorodihydrofluorecein diacetate (DCFDA), 3-(4,5-dimethylthiazol-2-yl)-2,5-diphenyl tetrazolium bromide (MTT), 5,5-dithio-bis(2-nitrobenzoic acid) (DTNB), Sodium hydroxide were procured from Sigma-Aldrich, USA. Enzyme-linked immunosorbent assay (ELISA) kits for TGF- $\beta$, IL-22, IL-1 $\beta$, IL-17A, and IL-6 were procured from Thermo scientific, USA. Enhanced chemiluminescence (ECL) reagent and nitrocellulose membrane were purchased from Biorad, USA. Fetal bovine serum (FBS), Roswell park memorial institute-1640 (RPMI1640) medium, Antibiotic-Antimycotic and TrypsinEDTA were purchased from GE Health care, USA. The primary antibodies such as anti-p-MAPK p44/42, antiMAPK p44/42, anti-p-SAPK/JNK, anti-SAPK/JNK, anti-p-MAPK p38, anti-MAPK p38, anti-p-GSK-3 $\beta$, anti-GSK-3 $\beta$, anti-p-Akt, anti-Akt, and anti-Cyclin D1 were purchased from Cell Signaling Technologies, USA. Anti- $\beta$-Actin and anti-Ki67, anti-mTOR, antip-STAT3, anti-PCNA as well as secondary antibodies such as anti-Rabbit and anti-Mouse antibodies were procured from Santa Cruz Biotechnology, USA. The anti-STAT3 antibody was obtained from Biorad, USA. Imiquimod cream (Marketed as Imiquad cream, 5\% w/w, Glenmark Pharmaceuticals Ltd., India) was purchased. All other chemicals were obtained commercially which were pure and analytical grade.

\section{Preparation and characterization of SeNPs}

SeNPs were prepared as per the procedure described earlier [30, 31]. Briefly, $5 \mathrm{ml}$ of $25 \mathrm{mM}$ Sodium selenite $\left(\mathrm{Na}_{2} \mathrm{SeO}_{3}\right)$ was mixed with $20 \mathrm{ml}$ of $25 \mathrm{mM} \mathrm{rGSH}$ containing $200 \mathrm{mg}$ bovine serum albumin (BSA). The $\mathrm{pH}$ of the obtained mixture was adjusted to 7.2. The 
red-colored solution obtained was dialyzed for $96 \mathrm{~h}$ against double distilled water to separate GSSG and free sodium selenite from SeNPs using the magnetic stirrer by changing the water every $24 \mathrm{~h}$. The SeNPs suspension was taken from the dialysis bag into a $50 \mathrm{ml}$ falcon tube and was subjected to centrifugation at $14,000 \mathrm{rpm}$ for $10 \mathrm{~min}$. The supernatant was disposed and $20 \mathrm{ml}$ of double-distilled water was added to the pellet and vortex for $1 \mathrm{~min}$ and subjected to centrifugation at $14,000 \mathrm{rpm}$ for $10 \mathrm{~min}$ and repeated this for 3-4 times to remove possible free sodium selenite and other reactants in nanoparticles. The size measurements were performed using the zeta analyzer (Malvern, UK). To determine the morphology and size, Transmission electron microscopy (TEM) (Hitachi, H-7500) was used. SeNPs were mixed and a small drop of SeNPs sample was taken and placed on parafilm, then the carbon-coated copper grid was placed for $5 \mathrm{~min}$. Then the excess of NPs was dried, and stained with $2 \%$ uranyl acetate for negative stain contrast. After preparation of nanoparticles the UV absorption was measured at $205 \mathrm{nM}$ using UV spectrophotometer by diluting water and dilution ratio was 1:10,000 and for the powder X-ray Diffraction (PXRD) patterns of samples were recorded by using $\mathrm{X}$-ray diffractometer (Philips X'pert MPD System) as per the previous method described [32]. Samples were illuminated using Ni-filtered $\mathrm{Cu}-\mathrm{K}$ at current of $30 \mathrm{~mA}$ with $40 \mathrm{kV}$ voltages. Data were obtained over $2 \theta$ scan ranging from 10 to 50 with a step time of $0.012^{\circ}$ steps.

\section{Topical gel formulation of SeNPs}

SeNPs were formulated as a gel for topical application with adequate viscosity. $0.75 \%$ Carbapol gel was prepared by mixing accurately weighed carbapol grade 934 in distilled water with continuous stirring and the gel is neutralized using triethanolamine with $\mathrm{pH} 6.8$ until a homogenous gel formation is achieved. Further, the gel is allowed to swell for $2 \mathrm{~h}$. Once the adequate consistency is achieved the specified amount of SeNPs were incorporated into the gel with continuous agitation. Further $100 \mathrm{mg}$ of gel which contain SeNPs 100 and $300 \mu \mathrm{g}$, respectively was topically applied on to the dorsal region of mice.

\section{Cell culture}

Human keratinocytes $(\mathrm{HaCaT})$ cell line was obtained as a kind gift sample from Dr. Munia Ganguly, IGIB New Delhi, India. The cells were grown in RPMI-1640 medium by supplementing with $10 \%$ FBS and $1 \%$ antibiotic-antimycotic. Further cells were incubated at $37{ }^{\circ} \mathrm{C}$ with $98 \%$ relative humidity and $5 \% \mathrm{CO}_{2}$. Cells were subcultures when attained $80-90 \%$ confluence.

\section{Determination of cytotoxicity by MTT assay}

The cytotoxicity induced by SeNPs was determined by MTT assay [33]. This assay detects the formation of formazan crystals by dehydrogenase enzymes of mitochondria and the cytotoxicity was determined based upon the absorbance [34]. Briefly, $\mathrm{HaCaT}$ cells were grown in 96 well plates and cells were treated with serially diluted SeNPs by two-fold dilutions with the concentrations ranging from 0.39 to $50 \mu \mathrm{g} / \mathrm{ml}$ and incubated up to $24 \mathrm{~h}$. Later cells were washed with PBS for the complete removal of SeNPs. Then MTT reagent $(0.5 \mathrm{mg} / \mathrm{ml})$ was mixed in respective media and incubated for $4 \mathrm{~h}$. DMSO was used to solubilize the formazan crystals and absorbance was measured at $570 \mathrm{~nm}$ (Spectramax M4, Molecular devices, USA).

\section{Microscopic evaluation of apoptosis}

Acridine orange (AO) staining evaluates the morphological changes in apoptotic cells by formation of blebs in the membrane, fragmentation and condensation of the nucleus. In AO staining, AO pervade all the cells and makes the nuclei appear green. DAPI (4', 6-diamidino2-phenylindole) is a nuclear stain and is frequently used as nuclear segmentation tool. The changes in the nucleus can be visualized in a fluorescent microscope, which is indicative of apoptosis [35, 36]. To visualize these changes, $\mathrm{HaCaT}$ cells were plated in 12-well plates and the following next day, cells were incubated with SeNPs at the concentrations of $0.5,1$ and $2.5 \mu \mathrm{g} / \mathrm{ml}$. After $1 \mathrm{~h}$, EGF $(50 \mathrm{ng} / \mathrm{ml})$ had been stimulated and further incubated for $24 \mathrm{~h}$, then stained with AO and DAPI. Then the images were captured at $\times 200$ by fluorescent microscope (Nikon Eclipse TiS, Japan).

\section{Cell cycle analysis}

PI staining was performed to evaluate the induction of cell cycle arrest in epidermal keratinocytes and then analyzed by flow cytometry [37]. In this method, $\mathrm{HaCaT}$ cells were seeded in 12 well plates and treated with SeNPs for $1 \mathrm{~h}$ followed by EGF induction and incubated further for $24 \mathrm{~h}$. After trypsinization, the cells were fixed in $70 \%$ ethanol and stored at $-20{ }^{\circ} \mathrm{C}$. Later the ethanol fixed cells were washed with PBS and incubated for $15 \mathrm{~min}$ in staining buffer which contains triton-X-100, PI, and RNAse enzyme) and then cells were vortexed and analyzed by flow cytometry (BD C6 Accuri flow cytometry, USA).

\section{JC-1 staining}

The modulation in the redox potential of the mitochondrial membrane can be determined by JC-1 staining [38] 
The shift in the emission of fluorescence will be observed from red to green, which depends on mitochondrial membrane potential $(\Delta \Psi \mathrm{m})$. Green fluorescence intensity develops due to "J monomers" which occurs at depolarized $\Delta \Psi \mathrm{m}$, while red fluorescence intensity develops due to "J aggregates", which are formed at high membrane potentials [39]. To test this effect, in this assay, $\mathrm{HaCaT}$ cells were plated at a cell density $4 \times 10^{4}$ in 12 well plates, and treated with SeNPs and incubated for $24 \mathrm{~h}$ in the presence of EGF stimulation. Later, these cells were stained with JC-1 dye ( $1 \mu \mathrm{M}$ for $30 \mathrm{~min})$ and it was quantitatively analyzed by flow cytometry.

\section{Alexa Fluor 488 Annexin V/Dead cell apoptosis assay}

Dead cell apoptosis assay is quick and suitable method for identification of apoptotic cells as Annexin V, being phospholipid binding protein has more affinity towards phosphatidyl serine, which moves from inner plasma membrane leaflet to outer leaflet in apoptotic cells and thereby these apoptotic cells can be quantitatively estimated [40] For this assay, Alexa Fluor ${ }^{\circledR} 488$ Annexin V/ Dead cell apoptosis kit (Thermo Fischer Scientific, USA) was used. Initially, the assay was optimized by seeding $\mathrm{HaCaT}$ cells at cell density $4 \times 10^{4}$ and allowed to adhere, and further treated with SeNPs $(0.5,1$ and $2.5 \mu \mathrm{g} / \mathrm{ml})$ for $1 \mathrm{~h}$ followed by stimulation with EGF and incubated for $24 \mathrm{~h}$. Then the assay was performed with aforementioned kit and followed the manufacturer protocol. Later the samples from all groups were analyzed by flow cytometry [41].

\section{DCFDA staining}

ROS formation in the cells can be determined by DCFDA staining [30]. In this method, $\mathrm{HaCaT}$ cells were seeded in 6-well plates at a cell density $8 \times 10^{4}$ and treated with SeNPs $(0.5,1$ and $2.5 \mu \mathrm{g} / \mathrm{ml})$ followed by EGF and incubated for $24 \mathrm{~h}$. To detect ROS levels, DCFDA $(10 \mu \mathrm{M})$ was added to the cells and incubated at $37{ }^{\circ} \mathrm{C}$ for $20 \mathrm{~min}$ in the dark. After trypsinization, cells were washed with PBS and subjected to flow cytometry. In another set of the experiment after the addition of dye, cells were visualized under the fluorescence microscope at $498 / 530 \mathrm{~nm}$ (excitation/emission) at $\times 200$ magnification and corresponding images were captured [37].

\section{Experimental animals}

Adult BALB/c mice (25-30 g) 6-8 weeks age were procured from Palamur Biosciences Pvt. Ltd, Mahabubnagar, India. Animals were grouped into $n=3$ per cage by providing aseptic and ambient conditions, with $12 \mathrm{~h}$ light and dark cycle. The study protocol was approved by IAEC and all the experiments were carried out according to CPSCEA guidelines, Government of India.

\section{IMQ induced psoriatic plaque model}

IMQ induced psoriasis-like skin inflammation is a widely accepted model that induces TLR-7/TLR-8 receptors [42]. Here, this model is used to study the effect of SeNPs on the morphological features of IMQ induced psoriasis mice. For this, mice were divided into 5 groups, consisting of 5 animals per group $(n=5)$. The grouping of animals were divided as Normal control group (NC), Imiquimod control group (IMQ), Standard tacrolimus group (TAC; $20 \mathrm{mg} / \mathrm{kg}$ topically), SeNPs at two doses which include low dose (SeNPL; $3 \mathrm{mg} / \mathrm{kg}$ ) and high dose $(\mathrm{SeNPH} ; 10 \mathrm{mg} / \mathrm{kg})$. IMQ was applied topically at a dose of $62.5 \mathrm{mg} /$ day per $5 \mathrm{~cm}^{2}$ and the topical treatment of SeNPs and TAC was begun from day 3 of IMQ application once daily on the shaved region of skin for 4 days and monitored daily up to 6 days. Skin fold thickness was measured by vernier calipers (Mitutoyo, Japan), on the other hand, erythema and scaling were graded independently from 0 to 4 scale (0-none; 1 -slight; 2 -moderate; 3-marked; 4-very marked) every alternate day on 0 , 2, 4, and 6th day to obtain Psoriasis Area Severity Index (PASI) [43]. After sacrifice, the skin tissue samples were collected and stored at $-80{ }^{\circ} \mathrm{C}$. For histopathology analysis, the samples were fixed in $10 \%$ formalin.

\section{Hematoxylin and Eosin (H\&E) staining}

$H \& E$ staining is used to visualize the histo-pathological changes that include nuclear, cytoplasmic and epidermal changes such as epidermal hyperplasia and keratinocyte proliferation and also examine extracellular matrix features in the tissues. Hematoxylin has a deep blue-purple color which stains nucleic acids. Whereas, eosin stains cytoplasmic proteins is pink color, nonspecifically. Fixed skin tissues were dehydrated by incubating in gradient alcohol and xylene. Then $5 \mu \mathrm{m}$ skin sections were sliced using a microtome (Leica, Germany). Further processing steps were performed according to the previous reports [24]. The images were captured at $\times 200$ and $\times 400$ magnification by a bright-field microscope.

\section{Spleen to body weight index}

Animal bodyweights were recorded every day until the completion of the study and after sacrifice spleen morphology was observed and captured. To obtain spleen to body weight index, spleen weights were measured and normalized with body weights and the results were expressed in $\mathrm{mg} / \mathrm{g}$ body weight.

\section{Immunofluorescence (IF) analysis}

IF analysis involves an antibody binding to the antigens of a cell or tissue and then the bound product is visualized based on fluorescence [44]. In this method, $5 \mu \mathrm{m}$ skin tissue sections were deparaffinized, rehydrated, washed, 
and treated with proteinase $\mathrm{K}$ for 15 min for unmasking the antigen, then $3 \%$ BSA blocking solution was used to eliminate non-specific binding portions from the sections and incubated with anti-STAT3 and anti-Ki67 (1:100 dilutions) primary antibodies overnight at $4^{\circ} \mathrm{C}$. The unbound antibody from tissue sections were washed with immune wash buffer thrice and probed with Fluorescein isothiocyanate (FITC) or Rhodamine conjugated anti-rabbit or anti-mouse secondary antibodies (1:200 dilutions) at room temperature for $1 \mathrm{~h}$ and then sections were washed and mounted with DAPI Flour shield ${ }^{\mathrm{TM}}$ histology mounting medium (Sigma-Aldrich, USA) and the proteins expression was observed under Leica TCS SP8 Laser Scanning Spectral Confocal Microscopy (Leica, Germany).

\section{Estimation of cytokines by ELISA}

The cytokine levels were measured by ELISA assay in skin tissue samples. Briefly, skin tissues were homogenized with Tris- $\mathrm{HCl}$ buffer with protease and phosphatase inhibitors and centrifuged at $12,000 \mathrm{rpm}$ at $4{ }^{\circ} \mathrm{C}$ for $10 \mathrm{~min}$. The supernatant from all tissues were collected and protein estimation was done by Bradford's reagent (Biorad, USA). Polystyrene 96 well plates were coated with TGF- $\beta$, IL-17A, IL-22, IL-1 $\beta$, and IL- 6 along with $100 \mu \mathrm{l}$ of antibodies diluted with coating buffer and incubated at $4{ }^{\circ} \mathrm{C}$ overnight. Later excessive and unbound antibody was removed by washing buffer and further blocked with BSA. Further $100 \mu \mathrm{l}$ of the tissue supernatant was incubated followed by the addition of detection antibody for $1 \mathrm{~h}$ at room temperature. Later, $100 \mu \mathrm{l}$ of Avidin-HRP solution was added per well and incubated for $30 \mathrm{~min}$. Then $100 \mu \mathrm{l}$ of trimethylbenzidine solution per well for $15 \mathrm{~min}$ and measured absorbance at 450 and $570 \mathrm{~nm}$, reaction was terminated by $1 \mathrm{M} \mathrm{H}_{3} \mathrm{PO}_{4}$. The difference between absorption was calculated and protein estimated in $\mathrm{pg} / \mathrm{mg}$.

\section{Western blotting analysis}

The western blotting was performed to study the effect of various signaling pathways involved in psoriasis. The protein was extracted from cells and skin tissues as described earlier with slight modifications [35]. Protein concentration was estimated by Bicinchonic acid (BCA) (Sigma-Aldrich, USA). Samples were loaded in SDSPAGE (sodium dodecyl sulfate-polyacrylamide gel electrophoresis), where proteins were separated according to the molecular weight and transferred to the Nitrocellulose membrane by Trans-blot ${ }^{\circledR}$ Turbo $^{\mathrm{TM}}$ Transfer starter system (Bio-Rad, USA). The membranes were placed in Ponceau stain for visualization of protein bands according to the molecular weights. Later, 3\% BSA blocking solution was added to avoid nonspecific binding of antibodies, followed by primary and secondary antibodies were added, respectively and washed with TBS-T for 3 times, 5 min each and blots were detected in Chemdoc imaging system (Vilber Fusion Fx, France) by using ECL as a substrate and images were quantified by ImageJ software, NIH, USA. $\beta$-Actin was used as housekeeping protein and respective totals were used for normalization.

\section{Statistical analysis}

Data are represented as mean \pm standard deviation (SD). Graphs were plotted using Graph Pad Prism version 6 (Graph Pad Software, San Diego, CA). Statistical significance was evaluated with a one-way analysis of variance with the Bonferroni post hoc test. Values of $\mathrm{P}<0.05$ was considered as statistically significant.

\section{Results}

\section{Synthesis and characterization of SeNPs}

After synthesizing of SeNPs, their size distribution was measured using Zetasizer and SeNPs were diluted $(100 \mu \mathrm{l}$ of SeNPs in $900 \mu \mathrm{l}$ of water) to make it a uniform dispersion free of agglomerates and the average size of the SeNPs were found to be $110.73 \pm 7.24 \mathrm{~nm}$ with a polydispersity index (PDI) of $0.146 \pm 0.03$ (Fig. 1a). SeNPs exhibited a negative charge with the zeta potential of $-18.50 \pm 0.59$ (Fig. 1b). Additionally, the size and shape of SeNPs were evaluated by TEM analysis, where SeNPs exhibited the spherical morphology (Fig. 1c). As shown in the Fig. $1 \mathrm{~d}$ to assess the absorption of SeNPs in the visible range the UV-visible spectrum analysis was performed and the results depict that SeNPs characteristic absorption peak was obtained at $205 \mathrm{~nm}$. The results from PXRD patterns depicts that the SeNPs exhibited sharp diffraction peaks as shown in the Fig. 1e which demonstrates the crystalline nature of SeNPs and these results are consistent with the previously documented data[32].

\section{SeNPs inhibits keratinocytes hyperproliferation by induction of apoptosis}

The homeostasis imbalance among cell differentiation, cell proliferation, and programmed cell death leads to keratinocyte hyperproliferation with shortened cell cycles $[45,46]$. In in vitro model, the immortalized $\mathrm{HaCaT}$ cells were chosen, to promote hyperproliferation and evasion of apoptosis, the cells were stimulated with EGF at $50 \mathrm{ng} / \mathrm{ml}$. To investigate the effect of SeNPs on EGF induced hyperproliferation, MTT assay was performed with SeNPs at $24 \mathrm{~h}$ time point at concentrations ranging from 0.39 to $50 \mu \mathrm{g} / \mathrm{ml}$ and further stimulated with EGF. We found a gradual concentration-dependent cytotoxicity and the $\mathrm{IC}_{50}$ value was found to be $3.06 \pm 0.02 \mu \mathrm{g} /$ $\mathrm{ml}$ (Fig. 1f). Further, the cell death mechanism induced by SeNPs was found to be through the induction of 
apoptosis. Morphologically phase-contrast imaging, AO and DAPI staining revealed that SeNPs treated cells significantly lost the morphology with prominent apoptotic features at 1 and $2.5 \mu \mathrm{g} / \mathrm{ml}$ concentration such as nucleus condensation, nuclear pyknosis, horseshoe-shaped nucleus (Fig. 2a-c).

\section{SeNPs induces cell cycle arrest with ROS mediated loss of $\Delta \Psi \mathrm{m}$ and induction of apoptosis}

Hyperbaric oxygen therapy, which increases the ROS generation in skin tissues has been successfully used as a potent anti-psoriatic therapy in severe psoriasis [47]. The significant ROS generation disrupts $\Delta \Psi \mathrm{m}$ and further induce the apoptotic pathway [48]. The JC-1 monomers formation as a result of the loss of $\Delta \Psi \mathrm{m}$ exhibits green fluorescence, while J aggregates in control cells exhibit orange fluorescence, SeNPs treatment for $24 \mathrm{~h}$ resulted in a shift in the fluorescence towards green, indicating loss of $\Delta \Psi \mathrm{m}$ (Fig. 3a). We next evaluated the effect of SeNPs on total cellular ROS by DCFDA staining in EGF stimulated cells. Figure 3b, c demonstrate that SeNPs treatment significantly increased ROS levels in cells, while the extent of ROS levels generated were quantified by flow cytometry, where SeNPs treated groups showed a shift of peak towards the right side. The DNA fragmentation is the strong evidence of apoptosis induction, which can be analyzed by sub G1 phase arrest. In the present study, from the flow cytometric analysis, it was found that SeNPs treatment concentration-dependently enhanced the DNA fragmentation which was detected by a sharp and discrete peak representing the subpopulation of "Sub G1" (apoptotic cells), we observed that accumulations of cells in Sub G1 peak with increased concentrations as compared to control cells. This was accompanied by a decrease in the proportion of $\mathrm{S}$ and $\mathrm{G} 2 / \mathrm{M}$ phase percentages (Fig. 4a). For the quantitative assessment of apoptosis, after treatment with SeNPs for $24 \mathrm{~h}$, cells were double-stained with annexin-V Alexa flour 488/PI. As illustrated in Fig. 4b, it was found that SeNPs treatment significantly increased the rate of early apoptosis $($ Annexin $+/ \mathrm{PI}-$ ) as well as late apoptosis (Annexin + / $\mathrm{PI}+)$ compared to control cells.

\section{SeNPs improve the phenotypic features of IMQ induced psoriatic skin lesions and attenuate splenomegaly}

On the day of sacrifice, the dorsal region of the skin from all the animal groups was monitored and images were captured. The dorsal skin of the IMQ applied mice group exhibited the signs of erythema after 1 day; the other psoriatic features such as scaling and thickening of the skin were observed after 2-3 days of IMQ application and a gradual increase in the severity was observed until the end of the study in comparison with normal control mice group. SeNPs gel treatment topically at both doses (3 and $10 \mathrm{mg} / \mathrm{kg}$ ) evidenced improved epidermal structure and the phenotypic changes are comparable to the TAC treated animals (Fig. 5a). On the other side, there was significant enlargement of spleen was observed following 6 days of IMQ application, which depicts the systemic inflammation. Following the treatment, a significant decrease in the IMQ induced splenomegaly was observed and the ratio of spleen weight to body weight index showed a reduction in spleen weights (Fig. 5b, c). As mentioned earlier, the signs of psoriasis (epidermal thickness, erythema, and scaling) on the dorsal skin were evaluated on days $0,2,4$ and 6 . The PASI scoring was graded from 0-4 depending on the severity of symptoms and improvement with the treatment. From Fig. 5d-f, it is clear that SeNPs treatment significantly ameliorated IMQ induced redness and scaling with the reduction in the thickness. Hence, there was a decrease in the scoring on the day 7 similar to TAC.

\section{SeNPs reverse the IMQ-induced acanthosis and improve dermal architecture}

After sacrifice, dorsal skin tissue sections from all the groups were evaluated for histological observations. Consistent with the literature, skin tissue sections from the IMQ group exhibited typical alterations recapitulating psoriasis in mice such as hyperkeratosis, parakeratosis, acanthosis with an elongation of rete ridges compared to control mice. Further, the topical SeNPs gel treatment significantly reduced the epidermal hyperproliferation and improved the epidermal structure to the nearly normal thickness (Fig. 6c) and morphology as compared with the IMQ group and the images were captured at $\times 200$ (Fig. 6a) and $\times 400$ magnification (Fig. 6b).

\section{SeNPs attenuate the inflammatory cytokines and inhibit inflammatory signaling cascade}

The proinflammatory cytokines play a vital role in psoriasis pathogenesis [49]. Correlating with the existing literature, we found a significant increase in the levels of IL-1 $\beta$, IL-6, IL-17A, IL-22, and TGF- $\beta$ cytokines in IMQ skin tissues. Our results demonstrate that these perturbed cytokines levels were significantly attenuated with SeNPs treatment (Fig. 7a-e). MAPKs are involved in signal transduction, proliferation, cell survival and immune-mediated inflammatory responses [50]. It has been demonstrated from the previous reports that there was increased activation of $\mathrm{p}-44 / 42, \mathrm{p}-\mathrm{SAPK} / \mathrm{JNK}$ and p-p38 MAPKs in psoriatic skins. In this study, we investigated possible signaling pathways modulated by SeNPs. Consistent with the previous observations, we found a significant increase in the MAPKs (p-p38, p-SAPK/JNK, 


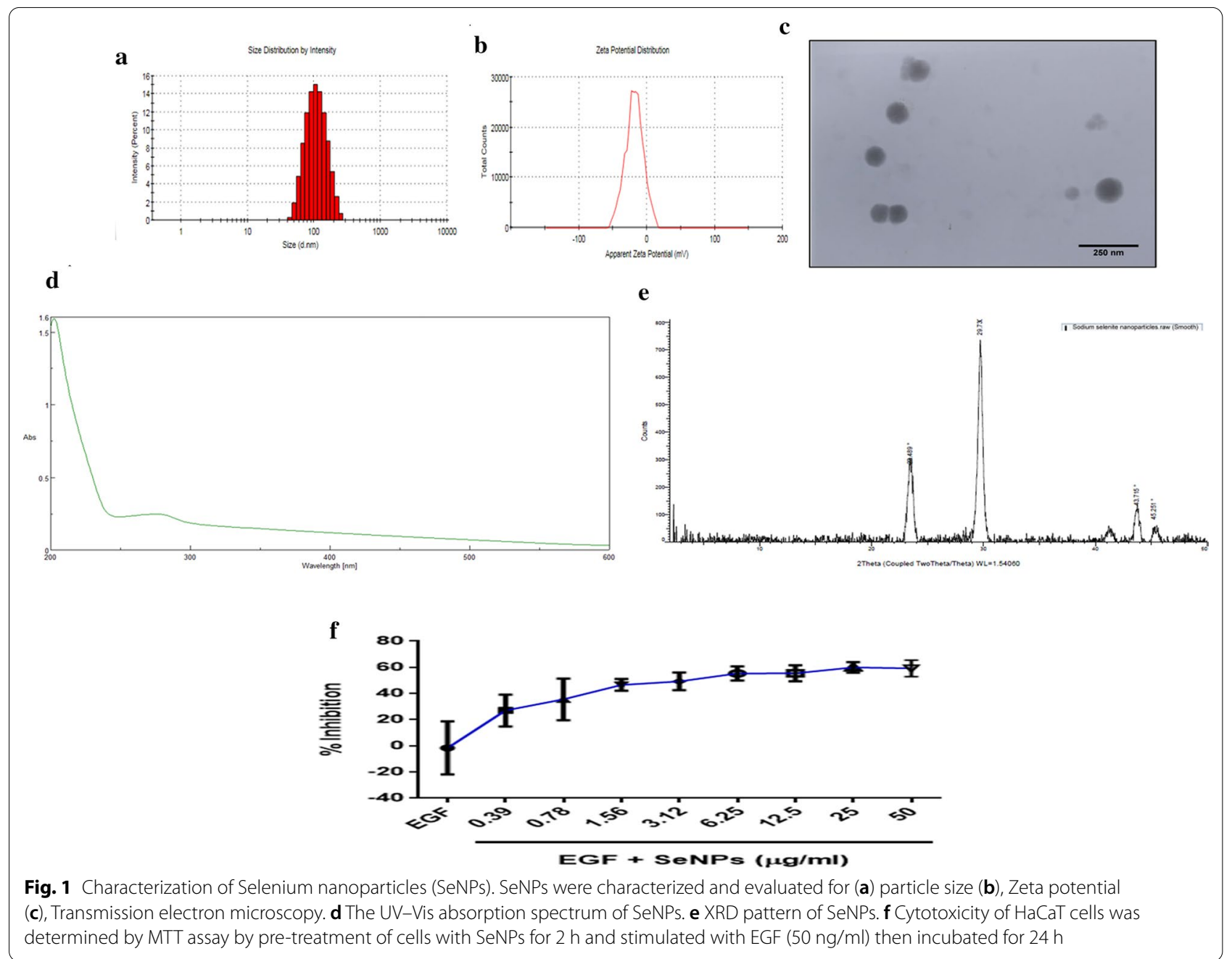

and p-p44/42) phosphorylation with EGF stimulation in $\mathrm{HaCaT}$ cells (Fig. $7 \mathrm{f}-\mathrm{i}$ ) as well as in the skin tissue sections from IMQ group (Fig. $7 \mathbf{j}-\mathrm{m}$ ). Following the treatment with SeNPs for $24 \mathrm{~h}$ followed by EGF stimulation in vitro and SeNPs topical administration in BALB/c mice resulted in decreased activation of MAPKs such as p44/42, p38, and SAPK/JNK phosphorylation in a dosedependent manner and a decrease in the phosphorylation of these MAPKs were observed.

\section{SeNPs abrogate hyperproliferation in $\mathrm{HaCaT}$ cells and skin tissues}

A key phenotypic endpoint in psoriasis is epidermal hyperplasia and the uncontrolled epidermal growth is strongly attributed by cytokines and growth factors which include IL-17, IL-22, EGF, and IGF-1, all together accelerates keratinocyte transit time and mitotic index up to tenfold compared to normal skin $[12,51]$. To test the molecular mechanism, $\mathrm{HaCaT}$ cells were stimulated with EGF at $50 \mathrm{ng} / \mathrm{ml}$ concentration to promote maximal growth and survival, followed by SeNPs treatment $(0.25$, 0.5 , and $1 \mu \mathrm{g} / \mathrm{ml}$ ) and then evaluated the protein expression by using western blotting. We observed a marked increase in the expression of proliferative markers expressions such as Ki67, Cyclin D1, and PCNA in EGF stimulated cells (Fig. 8a-h) and IMQ applied skin samples (Fig. 8i-p). A marked downregulation in the expression of these proliferative markers was found with SeNPs treatment. The Akt/mTOR activation and STAT3 signaling are known to promote acanthosis, which is implicated in the immunopathogenesis of psoriasis. In this context, we next investigated the effect of SeNPs on this pathway. We observed a significant increase in the phosphorylation of STAT3 and GSK-3 $\beta$, while Akt phosphorylation was observed at the Ser473 site. Furthermore, upregulation in the mTOR was observed in EGF and IMQ induction in keratinocytes and mouse skin tissues. The reduced epidermal thickness was further confirmed by immunofluorescence assay was performed in skin tissues from all experimental groups with PCNA and Ki67 antibodies. 


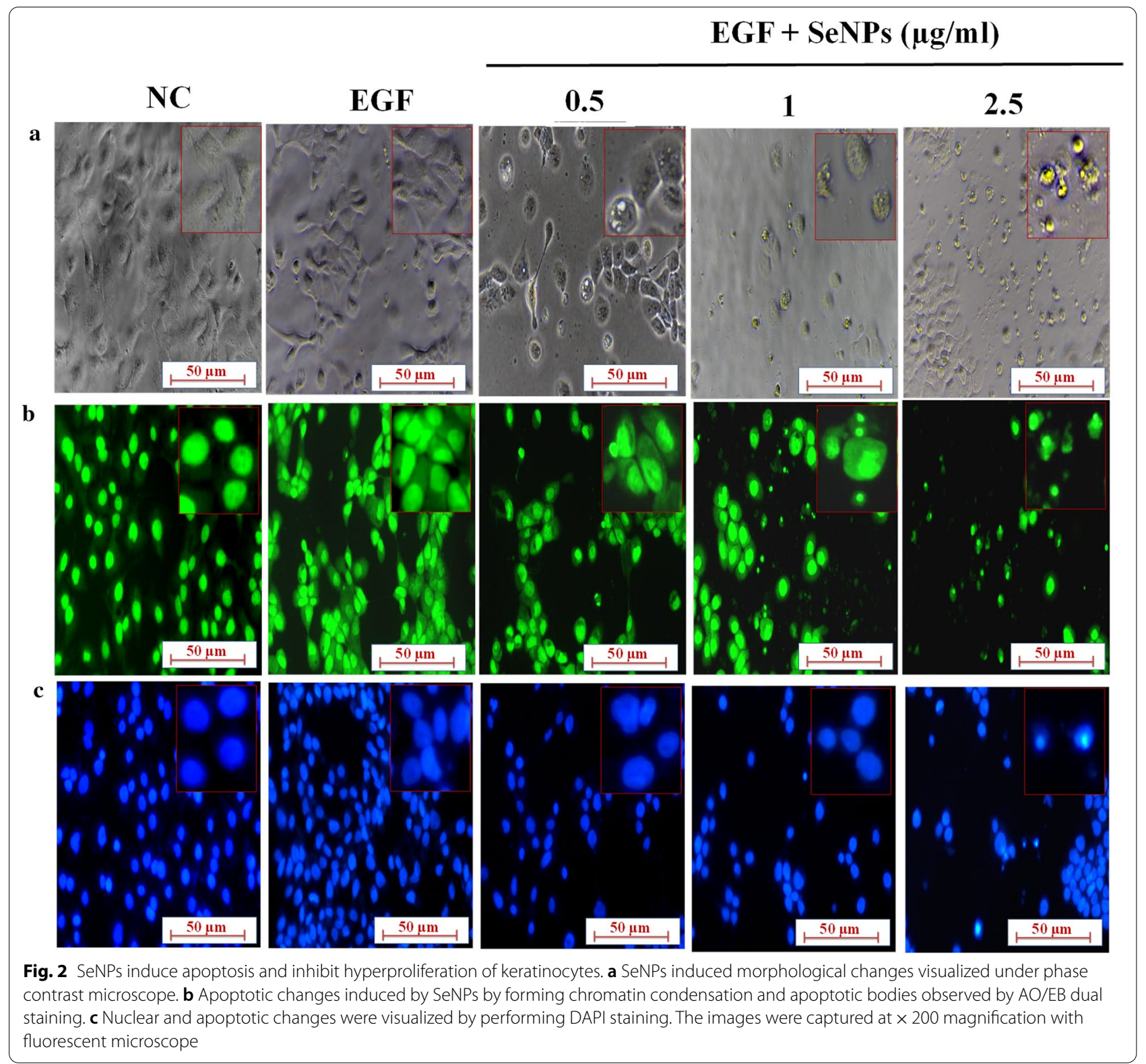

We found a significant PCNA and Ki-67 immunostaining in the IMQ group, while the expression was found to be reduced in SeNPs treatment at both the doses, indicating the marked reduction in epidermal hyperproliferation and this phenomenon reflects the decreased mitotic index (Fig. 9).

\section{Discussion}

Psoriasis is a chronic autoimmune disease characterized by thickened, scaly plaques as a result of aberrant keratinocyte hyperproliferation, which is accompanied by abnormal differentiation [52]. A vicious cycle between innate immune cells, $\mathrm{T}$ cells, and keratinocytes and a complex interplay among them are involved in psoriasis pathogenesis [53, 54]. Among these cells, innate immune cells initiate psoriasis through secretion of IL-23, which has a central role on the type Th17-cell axis [55]. At each step of the psoriasis molecular pathway, different inflammatory cytokines such as IL-6, IL-17, IL-22, and IL-23 are triggered, on the other side, growth factors such as EGF, VEGF, KGF, and IGF-1, which underscores the central role which predominantly drives epidermal hyperplasia $[12,56,57]$.

Over the last decade, the treatment options and understanding of the mechanism of psoriasis have witnessed a 


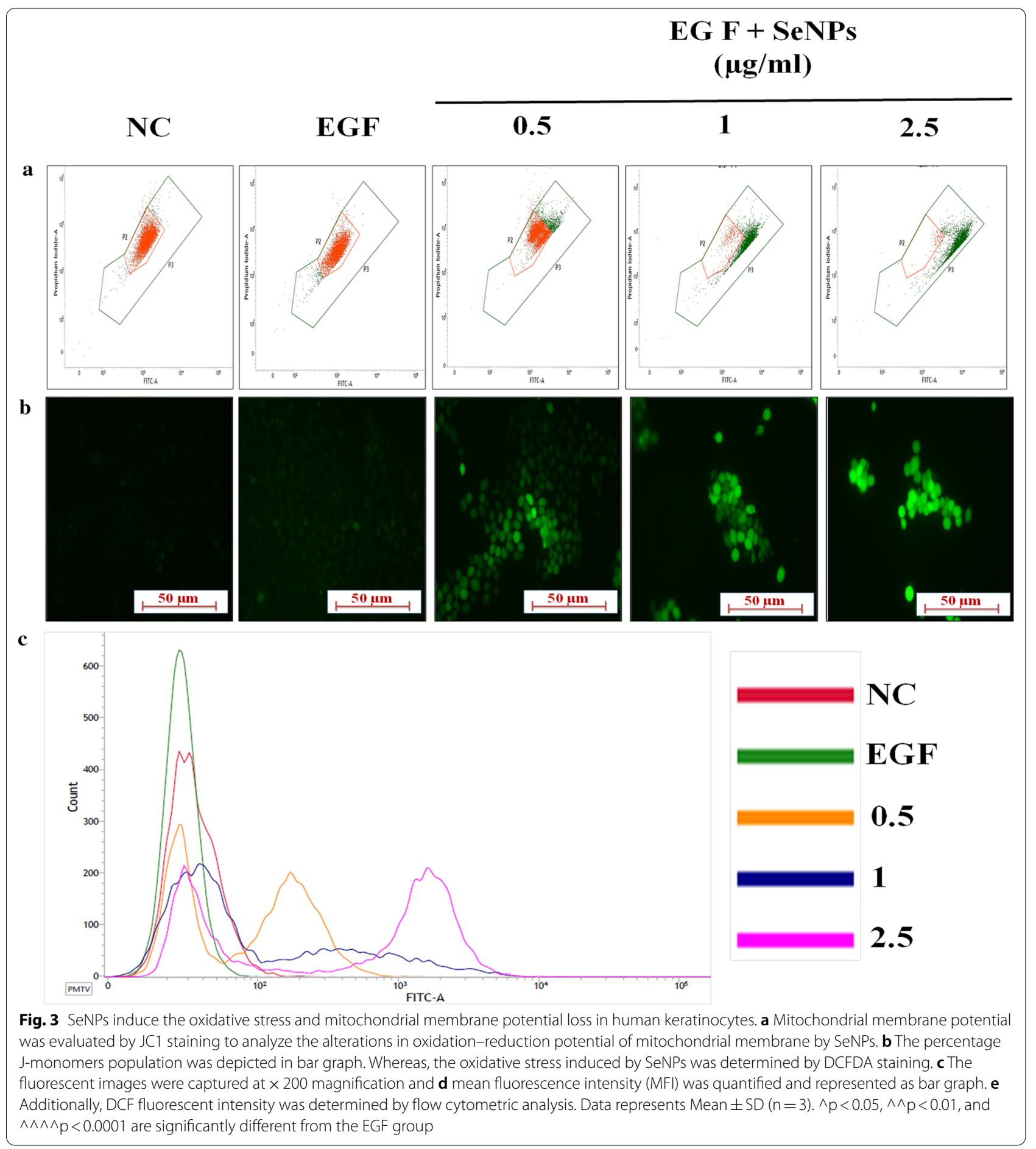

paradigm shift. However, despite the availability of wide treatment options, the adverse effects associated with long term usage remain a huge problem, which may have a negative impact on patient's quality of life [58, 59]. Hence, the novel therapeutic options warrant safe and therapeutically effective molecules.
Selenium (Se) is an essential trace element, which is a cofactor for thioredoxin reductase and glutathione peroxidase in animals [23]. The human genome contains 25 selenoprotein genes, which play a crucial role in immunomodulation, sperm motility and also prevent the risk of miscarriage $[22,28]$. These selenoproteins, 


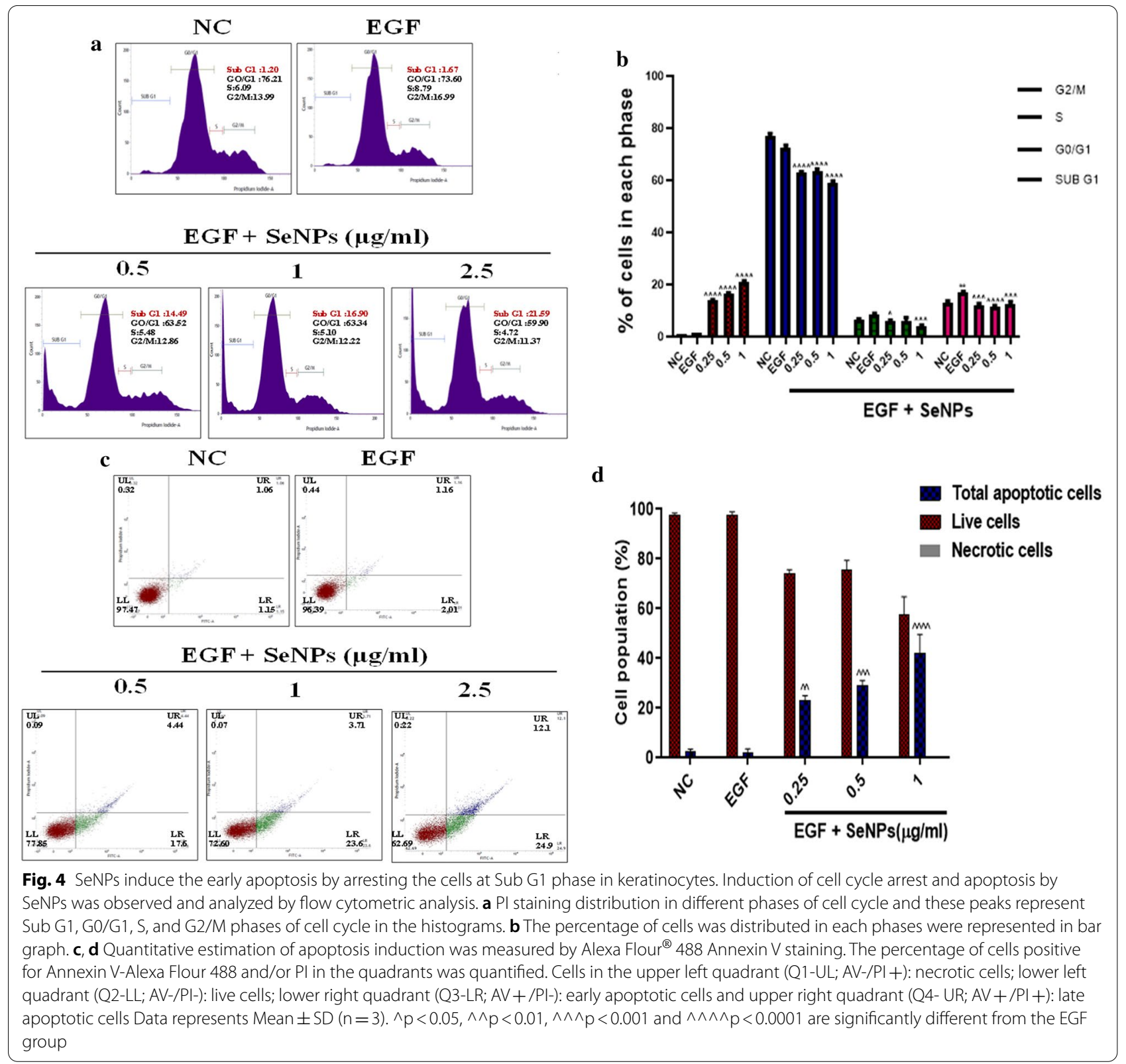

when prepared as nanoparticles, have been used successfully in abrogating several inflammatory disorders [28]. SeNPs exhibited potent anti-cancer properties in treating colorectal, lung and prostate cancers and the main mechanism behind the anti-cancer properties is mediated by induction of apoptosis and cell cycle arrest [60, 61]. A study by Sun D et.al, demonstrated that SeNPs when conjugated with luminescent Ru (II)-thiol selectively inhibited angiogenesis and tumor growth in hepatic carcinoma with minimal host toxicity [62]. Oral administration of SeNPs were found to induce the chemoprotective efficiency against cyclophosphamide induced genotoxicity and hepatotoxicity by the reduction in chromosomal aberrations in bone marrow, and DNA damage in lymphocytes and bone marrow and by balancing the redox state [63]. These fascinating properties of SeNPs prompted us to investigate the effect of SeNPs on immune-mediated benign epidermal hyperproliferation in psoriasis. SeNPs were prepared by the chemical reduction method and the prepared nanoparticles were spherical in morphology and exhibited negative charge. The recent study by Amani et.al, found that c Se nanoparticles has therapeutic effects on ischemic stroke through the protection of axons in hippocampus region, as well 


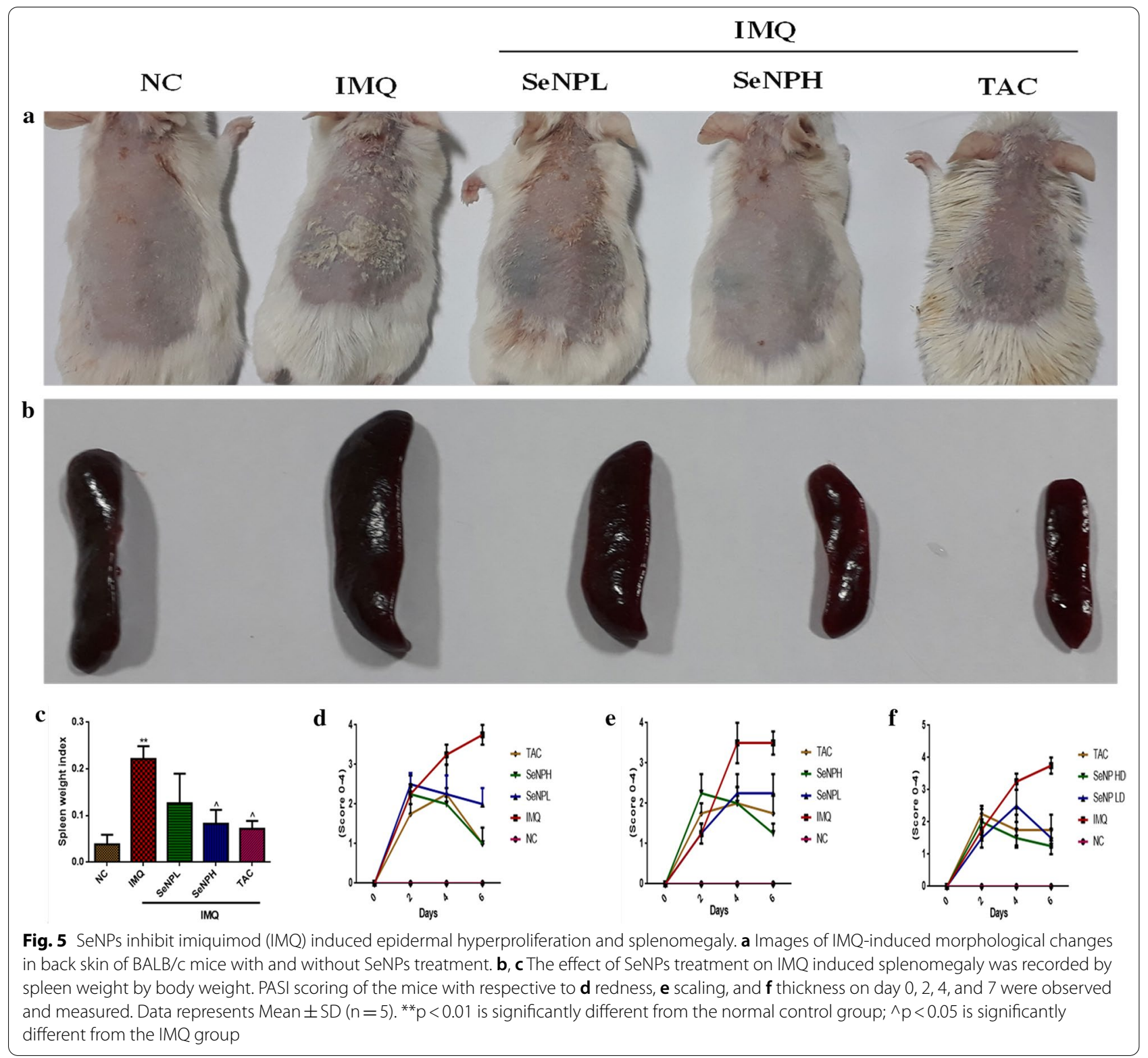

as myelination of hippocampal area along with the resolution of brain edema after cerebral ischemic stroke and with minimal side effects, through the regulation of wnt/ $\beta$-catenin signaling, mTOR, Tsc1/Tsc2 complex, FoxO1 hippo, Ubiquitin-proteasome system (ERK5) which are playing a prominent role in inflammation [64].

The abnormal hyperproliferation of psoriatic keratinocytes resists apoptosis [65-67]. Generally, apoptosis exhibits minimal inflammation and tissue damage; however apoptotic cell death based therapeutics has been exploited as one of the best antipsoriatic therapy. Previous reports demonstrated that apoptosis induction is the key mechanism behind the successful regression of psoriatic hyperplasia with conventional PUVA and methotrexate therapy $[33,34]$. To test a similar possibility initially, we have evaluated the effect of SeNPs on cell viability. Here, the hyperproliferation state of keratinocytes was mimicked by stimulating the cells with EGF and then cells were treated with SeNPs, where a gradual dose-dependent inhibition in the cell viability was observed. Next, we investigated the effect of SeNPs on apoptosis induction and we found prominent changes in the morphology of the cells with apoptotic features such as cytoplasmic shrinkage, nuclear fragmentation evident from $\mathrm{AO}$ and DAPI fluorescent staining as well as phasecontrast imaging. 


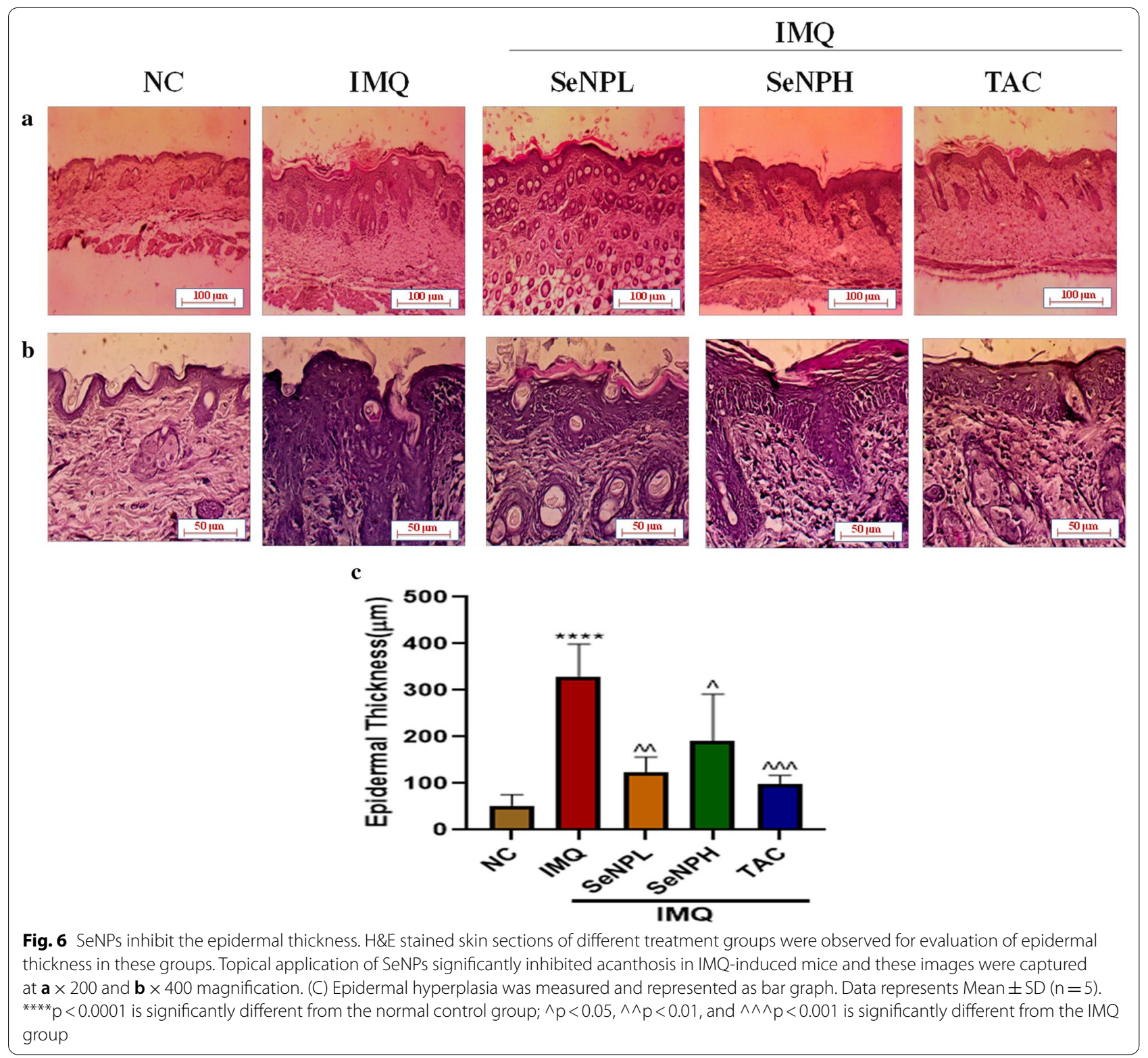

The increase in ROS generation leads to the simultaneous collapse of $\Delta \Psi \mathrm{m}$ and mitochondrial dysfunction. On the other side, intracellular ROS accumulation impedes cell proliferation by arresting cell cycle phases [68]. Previous reports showed that SeNPs can function as both prooxidant as well as antioxidant which is dependent on the dose and disease condition. At non lethal doses, Se typically induces apoptosis along with growth inhibitory properties by acting as prooxidant that induces oxidative stress in various cancers [69-73]. On the other side, in an ischemia reperfusion injury model it was found that Se NPs can effectively act as an antioxidant through the scavenging of different free radicals such as singlet oxygen, superoxide anion as well as nitric oxide [74]. The effect of SeNPs on HaCaT cells redox state with EGF stimulation was quantified by staining the cells with DCFDA, JC-1 and PI stain based cell cycle analysis. Our results showed that SeNPs treatment significantly elevates the levels of ROS in EGF stimulated $\mathrm{HaCaT}$ cells which were evaluated by a shift in the peak towards the green signal (right), which corresponds to high DCF molecules produced by the total cellular ROS by oxidation of DCFDA dye. Furthermore, JC-1 stain incorporates into healthy mitochondria forms $\mathrm{J}$ aggregates and fluoresces orange-red. When $\Delta \Psi \mathrm{m}$ collapses, JC-1 will remain as J-monomers and exhibit green fluorescence. 


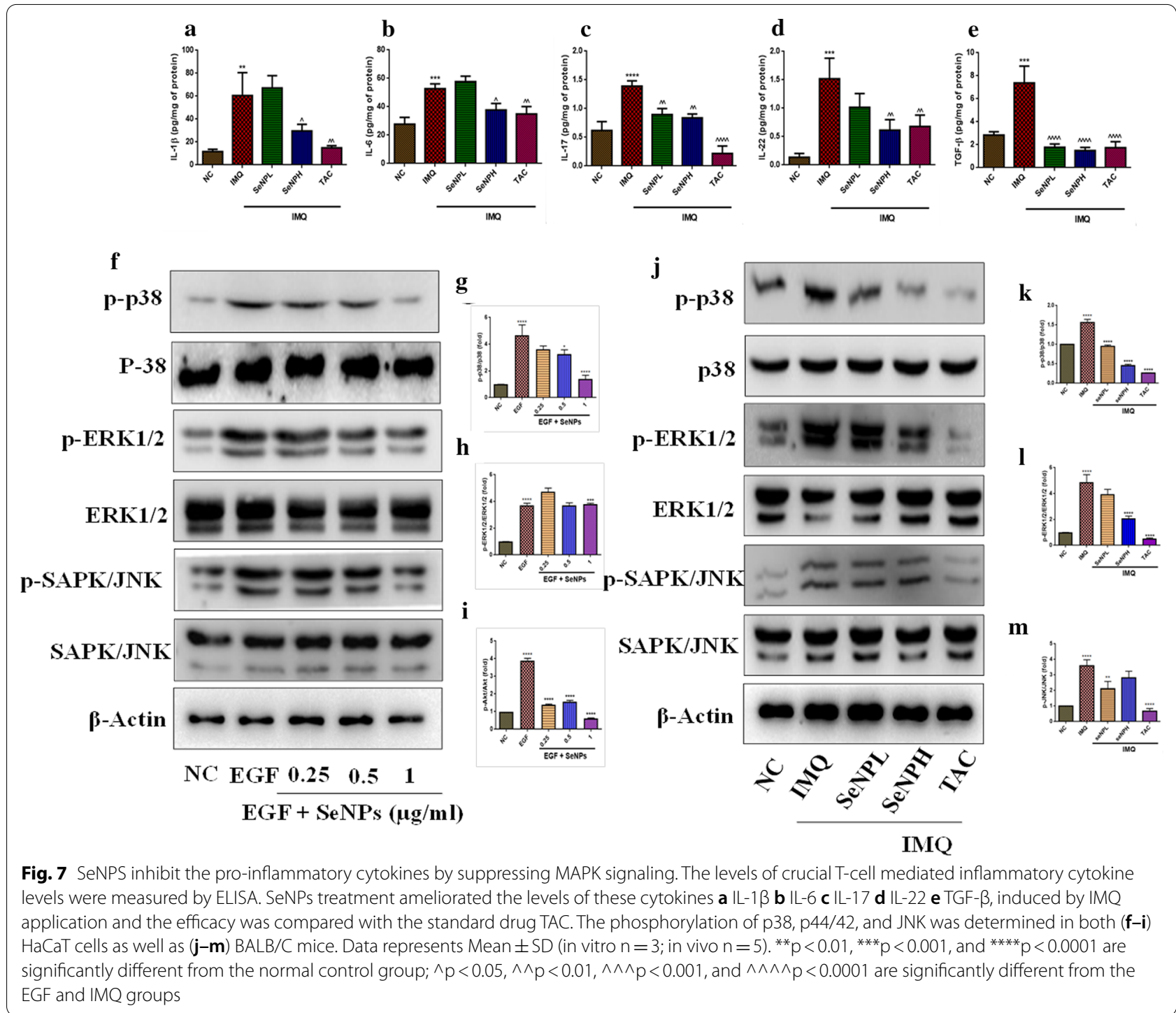

We observed a concentration dependent dissipation of $\Delta \Psi \mathrm{m}$ with an increase in the mitochondrial membrane depolarization. The formation of smaller base pair DNA fragments and single-strand cleavage events are the biochemical hallmarks of apoptosis [75]. From the cell cycle analysis data, a sharp increase in the discrete histogram peak representing the sub-G1 population was observed in SeNPs treated cells, compared to the control cell population. Next, annexin V Alexa flour 488 /PI assay was performed to detect early and late apoptosis in support of the previous results. Where, it was found that SeNPs treatment induced significant early apoptosis with an increase in concentration, while moderate late apoptosis was observed with negligible necrosis. Collectively, the present study suggests that SeNPs exerts its mechanism by a strong induction of apoptosis in EGF induced epidermal keratinocytes.
To investigate the effect of SeNPs on psoriasis in vivo, IMQ was used to induce psoriasis which is a widely accepted animal model, acts by binding to Toll-like receptors (TLR7 and TLR8), which involved in activation of innate immunity and stimulates adaptive immunity and recapitulates typical histopathological features in mice such as parakeratosis, acanthosis, scaling, erythema, skin thickening, and inflammatory cell infiltration which closely resembles human psoriasis [76]. Consistent with the previous literature, we have observed similar psoriatic features in mice upon the IMQ application. SeNPs were treated topically which were incorporated in a gel at 3 and $10 \mathrm{mg} / \mathrm{kg}$ doses respectively. Interestingly, our in vivo results evidenced that SeNPs daily topical application at both doses resulted in a reduction in plaque formation, erythema, and scaling. There was an increase in the skin thickness observed with IMQ 


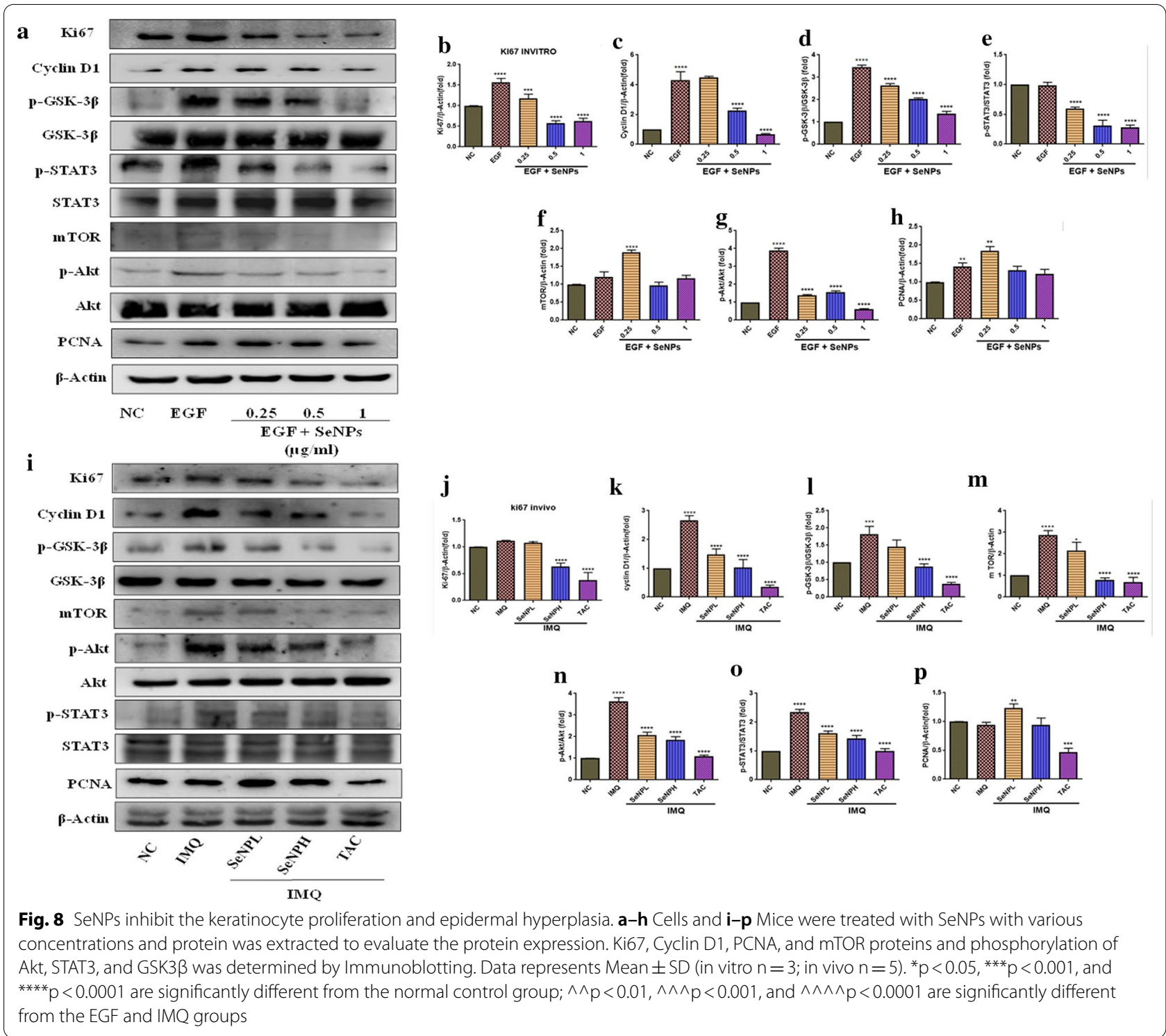

application in both the dorsal region and left ear measured by vernier calipers, while in treatment groups a decrease in both skin and ear thickness was observed and the results are comparable with the standard TAC. Based on these observations PASI scoring (erythema, thickening, and scaling) was given every alternate day. In IMQ applied animal groups a marked pathological change was observed in the epidermis and/or dermis such as an increase in epidermal keratinocytes protruded into the dermis as rete ridges with prominent parakeratosis along with the recruitment of leukocyte subsets into the skin. Microscopic evaluation SeNPs treated skin tissue sections underlined the superior ability in alleviating these pathological consequences. The systemic immune status is envisaged by the spleen, which is the largest immune organ, the state of inflammation in psoriasis enlarges the spleen due to a huge increase in the number of cells such as Th17/Th22 T cells [77]. Correlating with the previous studies, we have found a significant enlargement of spleen up to 3-folds compared to the normal control group. Topical SeNPs treatment significantly reduced the splenomegaly, which is indicative of alleviation in the inflammatory response.

The activation and upregulation of cytokines and chemokines produces a "feed-forward" inflammatory response in keratinocytes. IL- $1 \beta$ together with IL-23 are crucial in inducing Th17 and Th22 cell differentiation which further produces IL-17 and IL-22 cytokines. While IL- 6 cytokine primes Th17 in mediating hyper-proliferation in conjunction with IL-23 


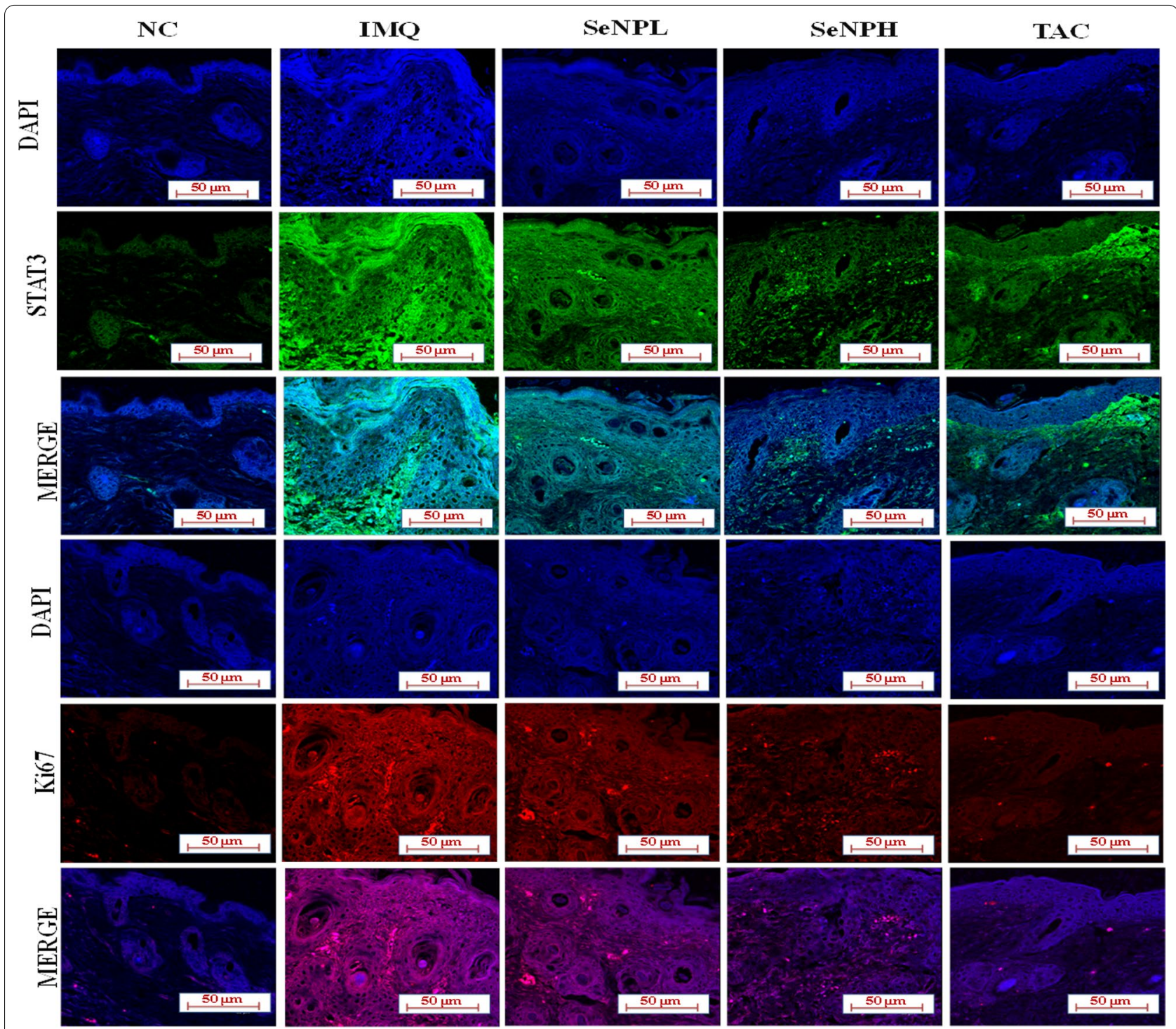

Fig. 9 SeNPs downregulate epidermal hyperplasia by suppressing STAT3 and Ki67 expression. Immunofluorescence analysis was performed in skin tissue sections to determine the expression of $\mathbf{a}, \mathbf{b}$ STAT3 and $\mathbf{c}, \mathbf{d}$ Ki67 using confocal microscopy. The images were captured at $\times 400$ magnification. Data represents Mean $\pm S D(n=3) .{ }^{* * *} p<0.0001$ are significantly different from the normal control group; $\wedge \wedge \wedge \wedge p<0.0001$ are significantly different from the IMQ group

cytokine [78]. Previous reports suggest that STAT3 plays a crucial role in Th17 and Treg cell differentiation and deregulation of STAT3 leads to the psoriasis pathogenesis through mediation of IL-17/IL-22/ IL-23 axis signaling; also the cytokines such as IL-6 and IL-21 are critical for Th17 cells maintenance that functions mainly through STAT3, also an impaired IL-17 production was observed in the absence of STAT3 [79, 80]. On another hand, a study by Han et al., reported the expression of wild-type TGF $\beta 1$ in the epidermis developed severe skin inflammation [81]. In support of this literature, our results evidenced a significant elevation in the aforementioned cytokines in the IMQ group. Moreover, SeNPs treatment significantly suppressed IL-1 $\beta$, IL-6, IL-17, IL-22, and TGF- $\beta$ cytokine levels. The aberrant activation of MAPK kinases which includes p38, ERK1/2, and JNK are involved in the pathogenesis of psoriasis [82]. As described above, following the previous studies increased phosphorylation levels of the $\mathrm{p} 44 / 42$, SAPK/JNK, and $\mathrm{p} 38$ proteins were observed following EGF treatment, as well as in skin tissues and these effects on phosphorylation were alleviated by SeNPs. Previous studies have shown that PI3K/Akt/mTOR and STAT3 are the main 


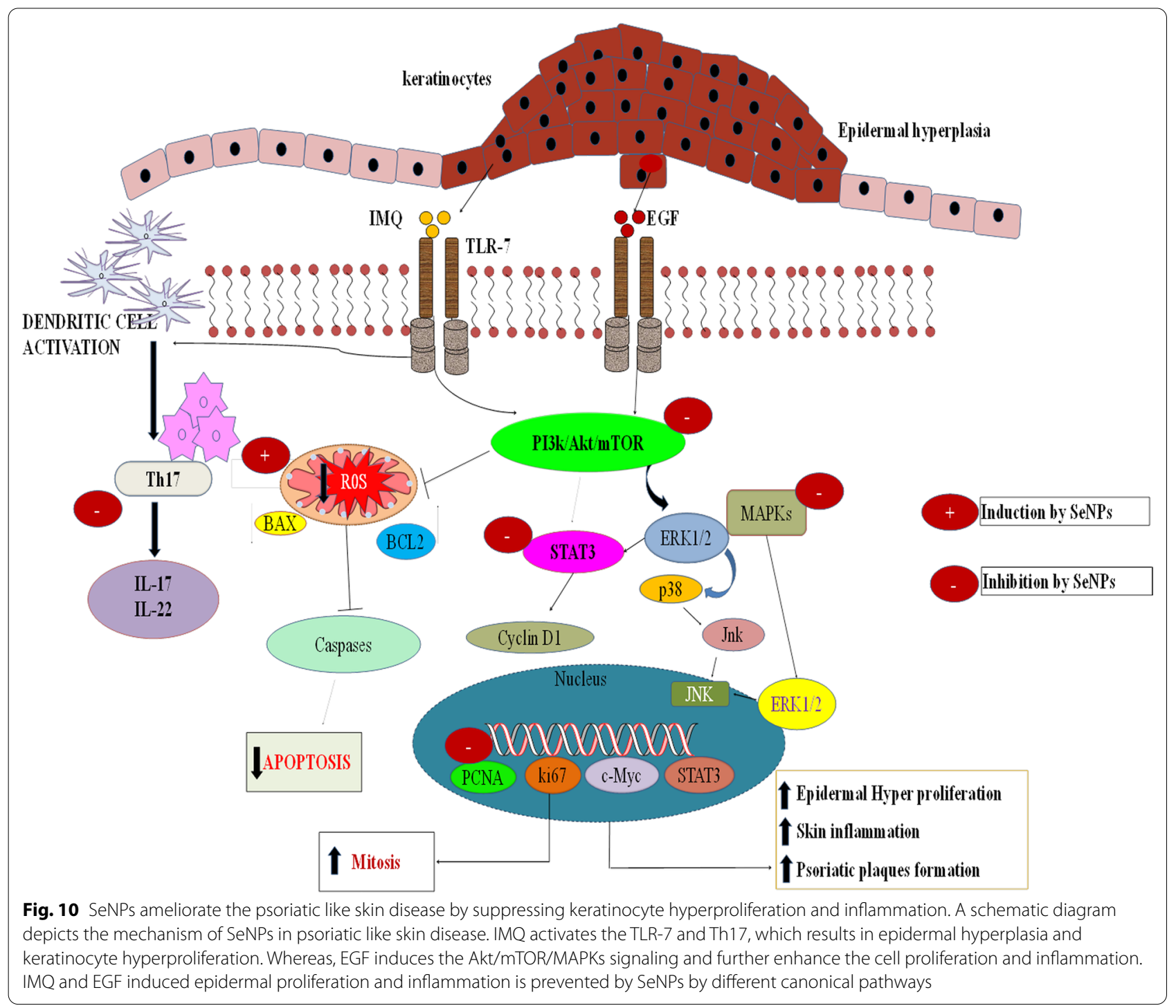

orchestrators of the immune response and keratinocyte hyperproliferation that sustains the chronic epidermal hyperplasia [83, 84]. In agreement with previous studies, both EGF stimulation and IMQ application increased these signaling cascades. On the other side, upregulation of Ki-67, PCNA and Cyclin D1 are the important hyperproliferative diagnostic hallmarks which differentiate psoriatic skin from normal skin. Molecularly, SeNPs treatment reduced the expression of cell growth promoters and proliferation markers such as Ki-67, PCNA, cyclin D1, and mTOR. A substantial reduction in Akt at ser 473, GSK-3 $\beta$, and STAT3 at Tyr 708 site was observed both in vitro and in vivo samples. Furthermore, we found that STAT3 and Ki67 activation in terms of localization and expression level in the thicker plaques of the epidermis of the IMQ group when compared to the normal epidermis with strong positive staining evaluated by immunofluorescence. Whereas SeNPs treated group showed a reduction in the immunopositivity and these results are in par with the standard TAC group.

In summary, our findings demonstrate that SeNPs primarily target keratinocytes in vitro by inducing apoptosis and thereby reduce keratinocytes hyperproliferation. Whereas, our in vivo findings demonstrate the effectiveness of SeNPs in alleviating IMQ induced acanthosis and further abrogated cytokines levels by targeting various signaling events involved in the psoriasis pathogenesis (Fig. 10).

\section{Conclusion}

Although many therapies are available as treatment options in psoriasis armamentarium, still there is an unmet need for new drugs with high efficacy and limited 
side effects. To the best of our knowledge, we report for the first time that SeNPs inhibit epidermal hyperplasia with potent anti-proliferative and anti-inflammatory activities. Our findings strongly suggest that SeNPs may be a potential therapeutic alternative in the treatment of psoriasis; the biological inertness is one of the advantages of SeNPs which may possess greater relevance in psoriasis with less adverse effects.

\section{Acknowledgements}

Authors are thankful to the Director of NIPER Hyderabad for supportive research activities. Authors also thankful to Department of Pharmaceuticals, Ministry of Chemicals and Fertilizers for providing the financial support and facilities to conduct the research.

\section{Authors' contributions}

VG and ST designed the experiments, performed the experimental work, analyzed the results, and wrote the manuscript. VP and GD performed part of the experimental work and/or analyzed the results. CG conceptualized the study and revised the manuscript. All authors read and approved the final manuscript.

\section{Funding}

This study was funded by Department of Pharmaceuticals, Ministry of Chemicals and Fertilizers, Government of India.

\section{Availability of data and materials}

The datasets used and/or analyzed during the current study are available from the corresponding author on reasonable request.

\section{Declarations}

\section{Ethics approval and consent to participate}

The study was approved by Institutional Animal Ethics Committee (IAEC) and Committee for the Purpose of Control and Supervision of Experiments on Animals (CPCSEA), Government of India (Gol). (Study protocol number: NIP/09/2018/RT/310).

\section{Consent for publication}

Not applicable.

\section{Competing interests}

The authors declare that they have no competing interest.

Received: 20 September 2020 Accepted: 24 March 2021 Published online: 13 April 2021

\section{References}

1. Luo Y, Hara T, Kawashima A, Ishido Y, Suzuki S, et al. Pathological role of excessive DNA as a trigger of keratinocyte proliferation in psoriasis. Clin Exp Immunol. 2020. https://doi.org/10.1111/cei.13455.

2. Al-Harbi NO, Nadeem A, Ahmad SF, Bakheet SA, El-Sherbeeny AM, et al. Therapeutic treatment with Ibrutinib attenuates imiquimod-induced psoriasis-like inflammation in mice through downregulation of oxidative and inflammatory mediators in neutrophils and dendritic cells. Eur J Pharmacol. 2020;877:173088.

3. MacDonald A, Burden AD. Psoriasis: advances in pathophysiology and management. Postgrad Med J. 2007;83(985):690-7.

4. Kastelan M, Prpic-Massari L, Brajac I. Apoptosis in psoriasis. Acta Dermatovenerol Croat ADC. 2009;17(3):182-6.

5. Wrone-Smith T, Mitra RS, Thompson CB, Jasty R, et al. Keratinocytes derived from psoriatic plaques are resistant to apoptosis compared with normal skin. Am J Clin Pathol. 1997;151:1321.

6. Parisi R, Symmons DPM, Griffiths CEM, Ashcroft DM. Identification and Management of Psoriasis and Associated ComorbidiTy (IMPACT) project team. Global epidemiology of psoriasis: a systematic review of incidence and prevalence. J Invest Dermatol. 2013;133(2):377-85.

7. Armstrong AW, Harskamp CT, Armstrong EJ. The association between psoriasis and hypertension: a systematic review and meta-analysis of observational studies. J Hypertens. 2013;31(3):433-42.

8. Armstrong AW, Harskamp CT, Armstrong EJ. Psoriasis and metabolic syndrome: a systematic review and meta-analysis of observational studies. J Am Acad Dermatol. 2013;68(4):654-62.

9. Armstrong AW, Harskamp CT, Armstrong EJ. The association between psoriasis and obesity: a systematic review and meta-analysis of observational studies. Nutr Diabetes. 2012;2:e54.

10. Furiati SC, Catarino JS, Silva MV, et al. Th1, Th17, and Treg responses are differently modulated by TNF-a inhibitors and methotrexate in psoriasis patients. Int J Sci Rep. 2019;9:1.

11. Rutz S, Eidenschenk C, Ouyang W. IL-22, not simply a Th17 cytokine. Immunol Rev. 2013;252:116-32.

12. Flisiak I, Szterling-Jaworowska M, Baran A, Rogalska-Taranta M, et al. Effect of psoriasis activity on epidermal growth factor (EGF) and the concentration of soluble EGF receptor in serum and plaque scales. Clin Exp Dermatol. 2014:39(4):461-7.

13. Lebwohl M, Ali S. Treatment of psoriasis. Part 1. Topical therapy and phototherapy. J Am Acad Dermatol. 2001;45(4):487-502.

14. Janagond A, Palit A. Biologicals in the treatment of psoriasis: the Indian perspective. BLDE Univ J Health Sci. 2017;2(1):9.

15. Sruamsiri R, Iwasaki K, Tang W, Mahlich J. Persistence rates and medical costs of biological therapies for psoriasis treatment in Japan: a real-world data study using a claims database. BMC Dermatol. 2018;18(1):5.

16. Moghimi SM, Hunter AC, Murray JC. Nanomedicine: current status and future prospects. FASEB J. 2005;19(3):311-30.

17. Sperling RA, Parak WJ. Surface modification, functionalization and bioconjugation of colloidal inorganic nanoparticles. Philos Trans R Soc Math Phys Eng Sci. 2010;368(1915):1333-83.

18. Bessar H, Venditti I, Benassi L, Vaschieri C, Azzoni P, et al. Functionalized gold nanoparticles for topical delivery of methotrexate for the possible treatment of psoriasis. Colloid Surface B. 2016;1(141):141-7.

19. David L, Moldovan B, Vulcu A. Green synthesis, characterization and anti-inflammatory activity of silver nanoparticles using European black elderberry fruits extract. Colloids Surf B Biointerfaces. 2014;122:767-77.

20. Murphy EC, Schaffter SW, Friedman AJ. Nanotechnology for Psoriasis Therapy. Curr Dermatol Rep. 2019;8(1):14-25.

21. Trofast J. Berzelius' discovery of selenium. Chem Int. 2011;33(5):16.

22. Rayman MP. The importance of selenium to human health. Lancet. 2000;356(9225):233-41.

23. Wadhwani SA, Utkarsha U, Shedbalkar RS, Chopade BA. Biogenic selenium nanoparticles: current status and future prospects. Appl Microbiol Biotechnol. 2016;100:2555-66.

24. Chaudhary S, Umar A, Mehta SK. Selenium nanomaterials: An overview of recent developments in synthesis, properties and potential applications. Prog Mater Sci. 2016;83:270-329.

25. Pi J, Jin H, Liu RuiYing, Song B, Qing Wu, et al. Pathway of cytotoxicity induced by folic acid modified selenium nanoparticles in MCF-7 cells. Appl Microbiol Biotechnol. 2013;97:1051-62.

26. Gao F, Yuan Q, Gao L. Cytotoxicity and therapeutic effect of irinotecan combined with selenium nanoparticles. Biomaterials. 2014;35(31):8854-66.

27. Tan L, Jia X, Jiang $X$. In vitro study on the individual and synergistic cytotoxicity of adriamycin and selenium nanoparticles against Bel7402 cells with a quartz crystal microbalance. Biosens Bioelectron. 2009;24(7):2268-72.

28. Khurana A, Tekula S, Saifi MA, Venkatesh P, Godugu C, et al. Therapeutic applications of selenium nanoparticles. Biomed Pharmacother. 2019:111:802-12.

29. Yazdi MH, Varastehmoradi B, Faghfuri E, Mavandadnejad F, Mahdavi M, Shahverdi AR, et al. Adjuvant effect of biogenic selenium nanoparticles improves the immune responses and survival of mice receiving 4T1 cell antigens as vaccine in breast cancer murine model. J Nanosci Nanotechnol. 2015;15(12):10165-72.

30. Sunkari S, Thatikonda S, Pooladanda V, Challa VS, Godugu C. Protective effects of ambroxol in psoriasis like skin inflammation: Exploration of possible mechanisms. Int Immunopharmacol. 2019;71:301-12. 
31. Bhattacharjee A, Basu A, Biswas J, Bhattacharya S. Nano-Se attenuates cyclophosphamide-induced pulmonary injury through modulation of oxidative stress and DNA damage in Swiss albino mice. Mol Cell Biochem. 2015;405(1-2):243-56.

32. Saeed M, Ansari MT, Kaleem I, Bajwa SZ, Rehman A, Bano K, Tehseen B, Jamil N, Zahoor M, Shaheen A, Taj A. Assessment of antimicrobial features of selenium nanoparticles (SeNPs) using cyclic voltammetric strategy. J Nanosci. 2019;19(11):7363-8.

33. Stockert JC, Blázquez-Castro A, Cañete M, Horobin RW, Villanueva A (2015) MTT assay for cell viability: intracellular localization of the formazan product is in lipid droplets. Acta Histochem. 2012;114(8):785-96.

34. Fotakis $G$, Timbrell JA. In vitro cytotoxicity assays: comparison of LDH, neutral red, MTT and protein assay in hepatoma cell lines following exposure to cadmium chloride. Toxicol Lett. 2006;160(2):171-7.

35. Thatikonda S, Pooladanda V, Godugu C. Repurposing an old drug for new use: niclosamide in psoriasis-like skin inflammation. J Cell Physiol. 2019;235(6):5270-83.

36. Tokala R, Bale S, Janrao IP. Synthesis of 1,2,4-triazole-linked urea/thiourea conjugates as cytotoxic and apoptosis inducing agents. Bioorg Med Chem Lett. 2018;28(10):1919-24

37. Thatikonda S, Pooladanda V, Sigalapalli DK, Godugu C. Piperlongumine regulates epigenetic modulation and alleviates psoriasis-like skin inflammation via inhibition of hyperproliferation and inflammation. Cell Death Dis. 2020;11(1):1-17.

38. Kumar NP, Vanjari Y, Thatikonda S, Pooladanda V. Synthesis of enamino2-oxindoles via conjugate addition between a-azido ketones and 3-alkenyl oxindoles: cytotoxicity evaluation and apoptosis inducing studies. Bioorg Med Chem Lett. 2018;28(22):3564-73.

39. Sivandzade F, Bhalerao A, Cucullo L. Analysis of the mitochondrial membrane potential using the cationic JC-1 dye as a sensitive fluorescent probe. Bio Protoc. 2019;9(1):e3128.

40. Hammill AK, Uhr JW, Scheuermann RH. Annexin V staining due to loss of membrane asymmetry can be reversible and precede commitment to apoptotic death. Exp Cell Res. 1999;251(1):16-21.

41. Tokala R, Thatikonda S, Sana S, Regur P, Godugu C, Shankaraiah N, et al. Synthesis and in vitro cytotoxicity evaluation of $\beta$-carboline-linked 2,4-thiazolidinedione hybrids: potential DNA intercalation and apoptosisinducing studies. New J Chem. 2018;42(19):16226-36.

42. Di Cesare A, Di Meglio P, Nestle FO. The IL-23/Th17 axis in the immunopathogenesis of psoriasis. J Invest Dermatol. 2009;129(6):1339-50.

43. Di T-T, Ruan Z-T, Zhao J-X. Astilbin inhibits Th17 cell differentiation and ameliorates imiquimod-induced psoriasis-like skin lesions in BALB/c mice via Jak3/Stat3 signaling pathway. Int Immunopharmacol. 2016;32:32-8.

44. Pooladanda V, Bandi S, Mondi SR, Gottumukkala KM, Godugu C, et al. Nimbolide epigenetically regulates autophagy and apoptosis in breast cancer. Toxicol In Vitro. 2018;51:114-28.

45. Komuves LG, Hanley K, Man M-Q, Elias PM, Williams ML, Feingold KR, et al. Keratinocyte differentiation in hyperproliferative epidermis: topical application of PPARa activators restores tissue homeostasis. J Invest Dermatol. 2000;115(3):361-7.

46. Jia J, Li C, Yang J, Wang X. Yes-associated protein promotes the abnormal proliferation of psoriatic keratinocytes via an amphiregulin dependent pathway. Sci Rep. 2018;8:1-11.

47. Kim H-R, Lee A, Choi E-J, Hong M-P, et al. Reactive oxygen species prevent imiquimod-induced psoriatic dermatitis through enhancing regulatory $T$ cell function. PLOS ONE. 2014;9:e91146.

48. Jo W-S, Jeong M-H, Jin Y-H. Loss of mitochondrial membrane potential and caspase activation enhance apoptosis in irradiated K562 cells treated with herbimycin A. Int J Radiat Biol. 2005;81(7):531-43.

49. Dyring-Andersen B, Honore TV, Madelung A, et al. IL-17A and IL-22 producing neutrophils in psoriatic skin. Br J Dermatol. 2017;177(6):e321-2.

50. Hommes DW, Peppelenbosch MP, van Deventer SJH. Mitogen activated protein (MAP) kinase signal transduction pathways and novel anti-inflammatory targets. Gut. 2003;52(1):144-51.

51. Wraight CJ, White PJ, McKean SC. Reversal of epidermal hyperproliferation in psoriasis by insulin-like growth factor I receptor antisense oligonucleotides. Nat Biotechnol. 2000;18(5):521-6.

52. Weng Z, Patel AB, Vasiadi $M$, Therianou $A$, et al. Luteolin inhibits human keratinocyte activation and decreases NF-KB induction that is increased in psoriatic skin. PLoS ONE. 2014;9:e90739.
53. Ippagunta SK, Gangwar R, Finkelstein D, Vogel P, et al. Keratinocytes contribute intrinsically to psoriasis upon loss of Tnip1 function. Proc Natl Acad Sci. 2016;113:E6162-71.

54. Albanesi C, Madonna S, Gisondi P, Girolomoni G, et al. The interplay between keratinocytes and immune cells in the pathogenesis of psoriasis. Front Immunol. 2018;9:1549.

55. Lowes MA, Bowcock AM, Krueger JG. Pathogenesis and therapy of psoriasis. Nature. 2007;445:866-73.

56. El-Komy M, Amin I, Zidan A, Kadry D, Zeid OA, Shaker O, et al. Insulin-like growth factor-1 in psoriatic plaques treated with PUVA and methotrexate. J Eur Acad Dermatol Venereol. 2011;25:1288-94.

57. Liew SC, Das Gupta E, Chakravarthi S. Differential expression of the angiogenesis growth factors in psoriasis vulgaris. BMC Res Notes. 2012;5(1):1-7.

58. Conrad C, Gilliet M. Psoriasis: from pathogenesis to targeted therapies. Clin Rev Allergy Immunol. 2018;54(1):102-13.

59. Kaushik SB, Lebwohl MG. Review of safety and efficacy of approved systemic psoriasis therapies. Int J Dermatol. 2019;58(6):649-58.

60. Rayman MP. Selenium in cancer prevention: a review of the evidence and mechanism of action. Proc Nutr Soc. 2005;64(4):527-42.

61. Zeng H, Combs Jr GF. Selenium as an anticancer nutrient: roles in cell proliferation and tumor cell invasion. J Nutr Biochem. 2008;19:1-7.

62. Sun D, Liu Y, Qianqian Yu, Qin X, et al. Inhibition of tumor growth and vasculature and fluorescence imaging using functionalized rutheniumthiol protected selenium nanoparticles. Biomaterials. 2014;35:1572-83.

63. Bhattacharjee A, Basu A, Ghosh P, Biswas J, Bhattacharya S. Protective effect of Selenium nanoparticle against cyclophosphamide induced hepatotoxicity and genotoxicity in Swiss albino mice. J Biomater Appl. 2014;29(2):303-17.

64. Amani H, Habibey R, Shokri F, et al. Selenium nanoparticles for targeted stroke therapy through modulation of inflammatory and metabolic signaling. Sci Rep. 2019;9(1):6044.

65. Eding CB, Enerback C. Involved and uninvolved psoriatic keratinocytes display a resistance to apoptosis that may contribute to epidermal thickness. Acta Derm Venereol. 2017;97(7):788-96.

66. El-Domyati M, Moftah NH, Ghada A. Evaluation of apoptosis regulatory proteins in response to PUVA therapy for psoriasis. Photodermatol Photoimmunol Photomed. 2013;29:18-26.

67. Elango T, Thirupathi A, Subramanian S, Ethiraj P, et al. Methotrexate treatment provokes apoptosis of proliferating keratinocyte in psoriasis patients. Int J Clin Exp Med. 2017;17:371-81.

68. Wang J, Luo B, Li X. Inhibition of cancer growth in vitro and in vivo by a novel ROS-modulating agent with ability to eliminate stem-like cancer cells. Cell Death Dis. 2017;8(6):e2887.

69. Weekley $\mathrm{CM}$, Harris HH. Which form is that? The importance of selenium speciation and metabolism in the prevention and treatment of disease. Chem Soc Rev. 2013;42(23):8870-94.

70. Wang H, He Y, Liu L, Tao W, Wang G, Sun W, Pei X, Xiao Z, Jin Y, Wang M. Prooxidation and cytotoxicity of selenium nanoparticles at nonlethal level in sprague-dawley rats and buffalo rat liver cells. Oxid Med Cell Longevity. 2020. https://doi.org/10.1155/2020/7680276.

71. Zhao G, Dong R, Teng J, et al. N-Acetyl-L-cysteine enhances the effect of selenium nanoparticles on cancer cytotoxicity by increasing the production of selenium-induced reactive oxygen species. ACS Omega. 2020;5(20):11710-20.

72. Zhao G, Wu X, Chen P, Zhang L, Yang CS, Zhang J. Selenium nanoparticles are more efficient than sodium selenite in producing reactive oxygen species and hyper-accumulation of selenium nanoparticles in cancer cells generates potent therapeutic effects. Free Radic Biol Med. 2018;126:55-66.

73. Ranjitha VR, Rai VR. Selenium nanostructure: progress towards green synthesis and functionalization for biomedicine. J Pharm Investig. 2021;51:117-35.

74. Amani H, Habibey R, Hajmiresmail SJ, Latifi S, Pazoki-Toroudi H, Akhavan O. Antioxidant nanomaterials in advanced diagnoses and treatments of ischemia reperfusion injuries. J Mater Chem B. 2017;5(48):9452-76.

75. Bortner CD, Oldenburg NB, Cidlowski JA. The role of DNA fragmentation in apoptosis. Trends Cell Biol. 1995;5(1):21-6.

76. Van der Fits L, Mourits S, Voerman JSA. (2009) Imiquimod-induced psoriasis-like skin inflammation in mice is mediated via the IL-23/IL-17 axis. J Immunol Baltim Md. 1950;182(9):5836-45. 
77. Chen YH, Wu C-S, Chao YH. Lactobacillus pentosus GMNL-77 inhibits skin lesions in imiquimod-induced psoriasis-like mice. J Food Drug Anal. 2017:25(3):559-66.

78. Onderdijk AJ, Baerveldt EM, Kurek D. IL-4 downregulates IL-1 $\beta$ and IL-6 and induces GATA3 in psoriatic epidermal cells: route of action of a Th2 cytokine. J Immunol. 2015;195(4):1744-52.

79. Calautti E, Avalle L, Poli V. Psoriasis: a STAT3-centric view. Int J Mol Sci. 2018;19(1):171.

80. Long Y, He Y, Jie F, Li S, Wu Y, Li Y, Du Q. Kuijieling-containing serum regulates Th17 and Treg cell differentiation by inhibiting STAT3 signaling in vitro. Based Complementary Altern Med Evid. 2019. https://doi.org/10. 1155/2019/7837989.

81. Han G, Williams CA, Salter K, Garl PJ, Li AG, Wang X-J. Role of TGF $\beta$ signaling in the pathogenesis of psoriasis. J Invest Dermatol. 2010;130(2):371-7.

82. Tan Q, Yang H, Liu E, Wang H. P38/ERK MAPK signaling pathways are involved in the regulation of filaggrin and involucrin by IL-17. Mol Med Rep. 2017;16(6):8863-7.
83. Andrés RM, Montesinos MC, Navalón P, Payá M, Terencio MC, et al. NF-kB and STAT3 inhibition as a therapeutic strategy in psoriasis: in vitro and in vivo effects of BTH. J Invest Dermatol. 2013;133(10):2362-71.

84. Chamcheu JC, Adhami VM, Esnault S. Dual inhibition of PI3K/Akt and mTOR by the dietary antioxidant, delphinidin, ameliorates psoriatic features in vitro and in an imiquimod-induced psoriasis-like disease in mice. Antioxid Redox Signal. 2016;26(2):49-69.

\section{Publisher's Note}

Springer Nature remains neutral with regard to jurisdictional claims in published maps and institutional affiliations.
Ready to submit your research? Choose BMC and benefit from:

- fast, convenient online submission

- thorough peer review by experienced researchers in your field

- rapid publication on acceptance

- support for research data, including large and complex data types

- gold Open Access which fosters wider collaboration and increased citations

- maximum visibility for your research: over $100 \mathrm{M}$ website views per year

At BMC, research is always in progress.

Learn more biomedcentral.com/submissions 